\title{
Prospective Childhood Risk Factors for Gang Involvement Among North American Indigenous Adolescents
}

Youth Violence and Juvenile Justice 2016, Vol. 14(4) 390-4I0 (C) The Author(s) 2015 Reprints and permission: sagepub.com/journalsPermissions.nav DOI: $10.1|77 /| 54|2040| 5585173$ yvj.sagepub.com

(SAGE

\author{
Dane S. Hautala', Kelley J. Sittner², \\ and Les B. Whitbeck'
}

\begin{abstract}
The purpose of the study was to examine prospective childhood risk factors for gang involvement across the course of adolescence among a large 8-year longitudinal sample of 646 Indigenous (i.e., American Indian and Canadian First Nations) youth residing on reservation/reserve land in the Midwest of the United States and Canada. Risk factors at the first wave of the study (ages I0-12) were used to predict gang involvement (i.e., gang membership and initiation) in subsequent waves (ages II-18). A total of $6.7 \%$ of the participants reported gang membership and $9.1 \%$ reported gang initiation during the study. Risk factors were distributed across developmental domains (e.g., family, school, peer, and individual) with those in the early delinquency domain having the strongest and most consistent effects. Moreover, the results indicate that the cumulative number of risk factors in childhood increases the probability of subsequent gang involvement. Culturally relevant implications and prevention/intervention strategies are discussed.
\end{abstract}

\section{Keywords}

American Indian, First Nations, gang membership, risk factors, longitudinal

Research on North American Indigenous (i.e., American Indian/Alaska Native and Canadian First Nations) populations has been largely absent from the mainstream criminological literature in general, and the gang literature specifically. Youth gangs, however, have been identified as an emergent and growing issue for tribal communities (Major, Egley, Howell, Mendenhall, \& Armstrong, 2004), and are estimated to be present on approximately one-quarter of United States reservations (Major \& Egley, 2002). Findings from cross-sectional studies indicate that $5-27 \%$ (Donnermeyer, Edwards, Chavez, \& Beuvais, 1996; Freng, Davis, McCord, \& Roussell, 2012; Whitbeck, Hoyt, Chen, \& Stubben, 2002) of Indigenous adolescents report gang membership

\footnotetext{
'Department of Sociology, University of Nebraska-Lincoln, Lincoln, NE, USA

${ }^{2}$ Department of Sociology, Oklahoma State University, Stillwater, OK, USA

\section{Corresponding Author:}

Dane S. Hautala, Department of Sociology, University of Nebraska-Lincoln, 204 Benton Hall, Lincoln, NE 68588, USA.

Email: dane.hautala@huskers.unl.edu
} 
during adolescence. Recent evidence from Whitbeck, Sittner Hartshorn, and Walls (2014) further indicates that upwards of two thirds of Indigenous adolescents reported being aware of gangs on their reservation/reserves. Despite this high prevalence and recent emergence, little is known about gang involvement among this group and risk factors that propel these youth into gangs. Given that gang membership often precedes many short-terms consequences such as violent victimization (Taylor, Peterson, Esbensen, \& Freng, 2007) and long-term consequences such as arrest, early parenthood, and dropping out of school (Krohn, Ward, Thornberry, Lizotte, \& $\mathrm{Chu}$, 2011; Pyrooz, 2014), research is warranted on risk factors for gang involvement among Indigenous youth.

Compared to their urban counterparts, the emergence of gangs on reservation/reserve land is a relatively recent phenomenon (Hailer \& Hart, 1999) which is believed to have started in the mid1990s, and continues to show growth (Major et al., 2004). Indigenous gangs tend to be smaller in size, less organized, and less violent than urban gangs (Hailer \& Hart, 1999; Major \& Egley, 2002). There is, however, evidence to suggest that this picture is changing. For example, the 2011 National Gang Threat Assessment (National Gang Intelligence Center, 2011) noted that some Indigenous gangs "are involved in serious crimes and violent activities and utilize Indian reservations to facilitate and expand their drug operation" (p. 34). Moreover, the 2011 National Gang Threat Assessment identified the Native Mob as one of the largest and most violent Indigenous gangs in the United States and the regions in which the current study takes place. Thus, as Hailer and Hart (1999) argued, Indigenous gangs appear to be transitional and evolving from small disorganized groups to organized gangs centered on criminal activity. Because Indigenous gangs are in their early developmental stages, prevention, and intervention programs may be highly effective at thwarting long-term growth and organization of gangs. To achieve this goal, sound empirical research is needed to better understand the issue at hand.

Perhaps the biggest limitation of previous Indigenous youth gang studies is the reliance on crosssectional data. An implicit assumption of the "risk factor" concept is that risk factors precede the actual outcomes they are expected to predict (Farrington, 2000). This indicates that prospective longitudinal designs are necessary in order to establish the temporal ordering between risk factors and subsequent gang involvement (Krohn \& Thornberry, 2008). In addition, gang membership itself may influence predictor variables in important ways (e.g., Drake \& Melde, 2014), making inferences from cross-sectional designs problematic. No longitudinal gang data, however, currently exist for rural and/or reservation/reserve communities. Given the dearth of data and methodological limitations of the existing Indigenous and rural gang literature (e.g., small and unrepresentative samples, cross-sectional designs, and reliance on law enforcement data), it is unclear whether risk factors for gang involvement among urban adolescents operate similarly for rural, reservation-residing Indigenous adolescents.

Taken together, these recent findings underscore the need to examine early prospective risk factors that are amenable to prevention and intervention efforts, which have yet to be thoroughly developed for Indigenous adolescent gang involvement. As such, the purpose of this study is to examine prospective childhood risk factors of later gang involvement (i.e., membership and initiation) among a large eight-wave/8-year longitudinal sample $(N=646)$ of Indigenous adolescents residing on reservation/reserve land in the Midwest of the United States and Canada. Because Indigenous (Freng et al., 2012) and non-Indigenous (Klein \& Maxson, 2006) youth are most vulnerable to joining gangs at the ages of 13-15, we focused on risk factors in late childhood (ages 10-12 years). In this article, we address several of the gaps in the Indigenous gang literature. First, we report on the longitudinal prevalence of gang involvement across adolescence (ages 11-18). Second, we examine a wider range of risk factors across multiple developmental domains (e.g., family, school, peer, and individual), than has been previously examined for Indigenous youth. Third, we assess the effect of accumulated risk across risk factors, which has been shown to be a robust predictor of gang involvement 
(e.g., Esbensen, Peterson, Taylor, \& Freng, 2009; Hill, Howell, Hawkins, \& Battin-Pearson, 1999; Thornberry, Krohn, Lizotte, Smith, \& Tobin, 2003).

\section{Literature Review}

Theriot and Parker (2008) argued that integrated theoretical perspectives are needed to give insight on the historical and contemporary context of Indigenous gang involvement. Vigil's $(1988,2002)$ multiple marginality theory appears to fit these criteria. The framework suggests that risk occurs on multiple ecological levels and accumulates to shape behavior across the early life course. Moreover, the multiple marginality approach is useful in contextualizing the broader sociohistorical factors that are salient among Indigenous populations. Vigil's (2002) theory posits that "macrohistorical and macrostructural forces-those that occur at the broader levels of society - lead to economic insecurity and lack of opportunity, fragmented institutions of social control, poverty, and psychological and emotional barriers" (p. 7). More recently, Whitbeck et al. (2014) argued for a model of Indigenous adolescent development, which posits that the various ecological domains identified by Vigil have been, and continue to be affected by historical cultural losses (e.g., forced relocation, boarding schools, creation of reservations/reserves, and racial microaggressions). These macro-historical processes, in turn, create a unique developmental context for Indigenous youth which is embedded in the social and cultural environments of reservations and reserves. These multiple levels of marginality that stem from historical cultural losses and continued economic marginalization on reservations/reserves may create fertile social and geographic conditions conducive to gang formation and involvement among Indigenous youth (Bell \& Lim, 2005; Grant \& Feimer, 2007; Grekul \& LaBoucane-Benson, 2008; Joseph \& Taylor, 2003). Both models would suggest that risk factors function similarly across social groups, but the conditions that shape and give rise to these risk factors may be unique among certain groups (e.g., race/ethnicity). This study is not a direct test of Vigil's theory but rather draws from it to place Indigenous youth gangs within a broader social context. Many of the risk factors we examine, however, are similar to Freng and Esbensen's (2007) quantitative assessment of Vigil's theory.

\section{Cumulative Risk Factors}

We posit that the early accumulation of risk across developmental domains will be a strong predictor of gang involvement during adolescence. We use an ecological approach, which has been advocated for in the development of theories explaining gang involvement (e.g., Howell \& Egley, 2005; Vigil, 1988, 2002), to assess cumulative risk for gang activity among Indigenous youth. The extant literature indicates that risk factors across multiple ecological domains predict gang involvement (see Klein \& Maxson, 2006; Krohn \& Thornberry, 2008 for reviews). Furthermore, no single risk factor necessarily pushes youth into gang involvement. Instead, the accumulation of risk is likely to have more predictive utility than individual risk factors (Farrington, 2000).

To the best of our knowledge, no research has examined the accumulation of risk factors and gang involvement among Indigenous youth. Yet a cumulative risk approach has been used in multiple urban gang studies (Esbensen et al., 2009; Hill et al., 1999; Thornberry et al., 2003), and shows strong evidence that higher accumulated risk during childhood/early adolescence increases the likelihood of subsequent gang involvement. In addition to cumulative risk across risk factors, two studies have examined cumulative risk across ecological domains (Esbensen et al., 2009; Thornberry et al., 2003). Both studies found that adolescents who possess risks in multiple domains had higher odds of gang membership. Moreover, the Esbensen, Peterson, Taylor, and Freng (2009) study showed that gang members possessed more risk within ecological domains (e.g., family, school, peer, and individual) than nongang-involved youth. In the next section, we review risk factors for 
gang involvement across multiple developmental domains. We limit our review to studies in which temporal ordering between risk factors and gang involvement was established. As noted previously, however, all of the research on Indigenous gangs is cross sectional.

\section{Risk Factors for Gang Involvement}

Family risk factors. The family is perhaps the most important social control mechanism that may push or pull youth into gang involvement (Vigil, 1988, 2002). Qualitative research among Indigenous gangs highlight the family as a key source of risk with family gang involvement providing a strong pull factor and other family problems providing important push factors that increase the allure of gangs (Grant \& Feimer, 2007; Grekul \& LaBoucane-Benson, 2008). Research on urban gangs has identified socioeconomic disadvantage and antisocial models within the family as important risk factors for joining a gang (Hill et al., 1999; Lahey, Gordon, Loeber, Stouthamer-Loeber, \& Farrington, 1999; Thornberry et al., 2003). Poverty and low educational attainment, all of which occur at high rates in many Indigenous communities (U.S. Census Bureau, 2006), create multiple levels of disadvantage within families and may weaken positive parenting practices that may be salient for Indigenous gang involvement (Bell \& Lim, 2005; Freng et al., 2012; Grant \& Feimer, 2007; Grekul \& LaBoucane-Benson, 2008). Specifically, factors such as poor parental monitoring (Freng et al., 2012), having a family member in a gang (Grant \& Feimer, 2007), and parent antisocial history (Freng et al., 2012) have been shown to be significant correlates of Indigenous gang involvement.

School risk factors. In addition to the family, Vigil's $(1988,2002)$ multiple marginality framework highlights schools as a second key social control mechanism which may inhibit or exacerbate the risk of gang involvement. Strong attachment and commitment to school may protect disadvantaged youth against antisocial behavior, whereas weak attachment or bonding to school may serve as a risk factor for delinquent activity and gang involvement (Dishion, Nelson, \& Yasui, 2005; Hill et al., 1999; Thornberry et al., 2003). One respondent in Grekul and LaBoucane's (2008) study of Indigenous gangs in Edmonton, Canada noted that youth who join gangs have little connection to conventional social institutions such as schools. This assertion has been supported by one quantitative study of Indigenous youth (Freng et al., 2012), in which weak school attachment was found to be a correlate of gang membership.

Peer risk factors. Peer influences are one of the most consistent and robust predictors of gang involvement (Hill et al., 1999; Klein \& Maxson, 2006; Vigil, 2002). During adolescence, familial influences give way to peers as the dominant socializing group (Thornberry, 1987). Peers provide opportunities for street socialization, which enhance the likelihood of gang formation and membership (Vigil, 1988). Associating with delinquent peers has been linked with earlier onset of gang membership (Lahey et al., 1999) and stable involvement with gangs (Craig, Vitaro, Gagnon, \& Tremblay, 2002). Similarly, associating with peers who are gang involved has been found to be a precursor to later gang membership among Indigenous youth (Grant \& Feimer, 2007). The rural context of the reservation/reserve is likely to shape the size, characteristics, and composition of peer networks (Whitbeck, Sittner Hartshorn, \& Walls, 2014). For example, adolescents living on the reservation/reserve may be embedded in small peer cohorts that they have grown up with. Antisocial peer associations, then, may be a highly influential and less malleable predictor of gang involvement among this group (Freng et al., 2012; Grant \& Feimer, 2007).

Compared to research on delinquent peer associations, few studies have examined early dating as a risk factor for gang involvement. Heterosexual romantic relationships often take place within mixed-sex peer networks and have important developmental consequences (Collins, 2003). Indeed, early dating and sexual behavior have been shown to increase the odds of gang membership 
(Thornberry et al., 2003). At present, we could locate no research that examines early dating as a correlate of gang involvement among Indigenous youth.

Individual risk factors. Individual risk factors such as stress exposure and negative emotions may stem from marginality in other life domains. According to Vigil's theory, gang involvement may be an adaptive response to these multiple sources of individual-level marginality. Numerous psychosocial stressors have been associated with gang involvement. For example, prior research has found negative life events to be a risk factor for gang involvement among urban (Thornberry et al., 2003) and Indigenous (Whitbeck et al., 2002) samples. Moreover, perceived racial discrimination has been linked with gang-related activity among rural Indigenous adolescents (Whitbeck et al., 2002). Given the centrality of race/ethnicity in gang involvement (Freng \& Esbensen, 2007; Vigil, 2002), early experiences of perceived racial discrimination may be a strong risk factor for later gang involvement.

In addition to stressful experiences, negative affective states, and neurobehavioral factors such as hyperactivity/impulsivity have been shown to increase the odds of gang involvement. Negative emotionality and neurobehavioral problems may create a propensity for gang involvement by increasing the likelihood of delinquent coping responses (Agnew, 1992) and reducing self-control (Unnever, Cullen, \& Pratt, 2003). Studies among urban youth have found depressive symptoms (Thornberry et al., 2003) and anger (Peterson \& Morgan, 2014) to be associated with later gang membership. In addition to negative emotionality, numerous studies among urban adolescents have found that hyperactivity and impulsivity (Craig et al., 2002; Dupéré, Lacourse, Willms, Vitaro, \& Tremblay, 2007; Hill et al., 1999) increase the odds of gang membership. Few studies have examined these psychosocial correlates of gang involvement among Indigenous youth.

Early delinquency. In addition to psychosocial risk factors, general delinquent behavior and early substance use initiation have been shown to be dynamic risk factors for later gang membership (Gordon et al., 2004; Lahey et al., 1999). Several studies have found delinquency to be a significant correlate of gang membership among Indigenous youth (Donnermeyer et al., 1996; Freng et al., 2012; Whitbeck et al., 2002). Moreover, Indigenous adolescents tend to initiate substance use at earlier ages than other racial and ethnic groups (Bachman et al., 1991), and substance use has been found to be a significant correlate of gang involvement among this group (Donnermeyer et al., 1996; Whitbeck et al., 2002). Because gang involvement itself may increase delinquent behavior (the facilitation hypothesis - Thornberry, Krohn, Lizotte, \& Chard-Wierschem, 1993), establishing proper temporal ordering is necessary to better understand delinquency and early substance use as potential risk factors for gang involvement among Indigenous youth.

\section{Purpose and Hypotheses}

To summarize, the limited cross sectional and qualitative work among Indigenous adolescents suggests that the risk factors for gang involvement may be similar to those identified in the longitudinal urban gang literature. There are, however, several risk factors that have not been examined for Indigenous youth gang involvement (e.g., psychosocial, neurobehavioral, and early dating factors), nor has the temporal ordering of risk factors and gang involvement been established. This latter point is important because risk factors have the potential to be influenced by gang involvement (e.g., gang involvement increases delinquency and rather than delinquency increasing the odds of gang involvement), making inferences from cross-sectional designs problematic in identifying causal predictors (Drake \& Melde, 2014). In this study, we investigate the cumulative effects of a wide range of risk factors identified in the previous Indigenous and urban gang literature on later gang involvement among a large prospective sample of Indigenous youth residing in the Midwest of the United States 
and Canada. We examine two general hypotheses. First, we hypothesize that each childhood risk factor (e.g., delinquent peer associations, substance use, etc.) measured at the first wave of the study will increase the odds of gang involvement at subsequent waves. Second, the cumulative number of risk factors is hypothesized to increase the likelihood of gang involvement. This takes into account the possibility that even if each risk factor does not significantly increase risk by itself, the cumulative effect of these factors may increase the odds of gang involvement. Drawing from Thornberry, Krohn, Lizotte, Smith, and Tobin (2003), we use an expanded set of conceptual domains to include family characteristics, school adjustment, peer relationships, individual characteristics, and early delinquency/substance use.

\section{Method}

\section{Sample}

The eight-wave longitudinal study from which the data for the present study were drawn was designed in partnership with seven U.S. reservations and Canadian First Nations reserves (for more details on the study design, see Whitbeck et al., 2014). Although participants were recruited from different sites, all participants are members of the same cultural group and share a common cultural tradition and language with only minor variations in dialects. As part of confidentiality agreements, the names of the cultural groups and reservations/reserves are not identified, nor are any attempts made to make comparisons across study locations. At each site, Tribal Council-appointed advisory boards were responsible for handling personnel issues, advising the research team on questionnaire development, and reviewing and approving reports and presentation proposals. All participating staff on the reservations and reserves (i.e., interviewers and site coordinators) were approved by advisory boards and were either enrolled tribal members or spouses of enrollees. Interviewers for this project were trained concerning methodological guidelines of personal interviewing and all were certified for work with human subjects.

At the beginning of the study, each community provided a list of families of tribally enrolled children aged 10-12 years who lived on or proximate to (within 50 miles) the reservation/ reserve. The research team attempted to contact all families with an eligible subject for the study within the specified age range to achieve a population sample. Families for this study were recruited through personal interviewer visits during which they were presented a traditional gift, an overview of the project, and an invitation to participate. For those families who agreed to participate, both the study adolescent and at least one adult caretaker (and in some cases, two adults) were given US\$20 upon completion of the interviews. The response rate for the initial baseline interviews was $79.1 \%$. Recruitment and incentive procedures were approved both by advisory boards appointed by Tribal Councils and the University of Nebraska Institutional Review Board.

The data for this study come from Waves 1 through 7 which were collected in 2002-2011. At Wave 1 , the sample was evenly split by gender ( $50.5 \%$ females and $49.5 \%$ males), and the average age was $11(M=11.10$; standard deviation $[S D]=0.83)$. Moreover, just over one tenth of the adolescents were living in a remote community $(10.5 \%)$, meaning the communities are not fully accessible by road at all times of the year. A similar proportion reported living off reservation/reserve land, but within 50 miles (14.1\%). A total of 13 adolescents (1.9\%) reported lifetime gang involvement at the first wave of the study. Because the purpose of the study is to examine risk factors preceding gang involvement, these cases were eliminated from the sample. In addition, another 15 respondents $(2.2 \%)$ were missing on the dependent variable — gang involvement — at all waves and were not included in the analyses. Complete data on the gang involvement measures were available for 646 participants (95.8\% of the total Wave 1 sample). At Waves 2, 3, 5, and 7 (which is when the 
gang items were administered), the study retention rates were $96.6 \%, 95.4 \%, 91.5 \%$, and $86.2 \%$, respectively.

\section{Dependent Variable}

Esbensen, Winfree, He, and Taylor (2001) argued that self-nomination is a good measure of distinguishing gang-involved and nongang youth. More recently, Decker and colleagues (Decker, Pyrooz, Sweeten, \& Moule, 2014) found that self-nomination was a strong predictor of multiple dimensions of gang embeddedness (e.g., frequency of gang contact and proportion of friends in gang) and distinguishes between individuals currently in a gang and those who have disengaged from a gang. In addition to gang membership, several scholars have argued that a wider range of gang-related items are needed to more reliably measure the construct of gang involvement (e.g., Dishion et al., 2005). We opted to examine a broader measure of gang involvement that includes both gang membership and gang initiation. A majority of gangs have some initiation process (Curry, Decker, \& Pyrooz, 2014), which signals formal entry into a gang (Vigil, 1996). There is also limited evidence among Indigenous samples indicating that small informal peer groups (crews) do not have any initiation process, whereas gangs do (Armstrong et al., 2002). If correct, this suggests that our included measure of going through a gang initiation taps into some form of general gang involvement rather than simply hanging out with gang members. Moreover, a similar initiation measure has been used in the National Longitudinal Study of Adolescent Health (Add Health), which asks whether youth have been initiated into a named gang (e.g., Barnes, Beaver, \& Miller, 2010; McNulty \& Bellair, 2003). More adolescents in this sample reported going through a gang initiation than they reported actual gang membership, which has been found in previous research among Indigenous youth (Whitbeck et al., 2002). As such, we found it necessary to examine similarities and differences between these two indicators of gang involvement.

We examined two variations of our dependent variable. First, at Waves 1, 2, 3, 5, and 7 (Waves 4, 6 , and 8 were mental health diagnostic waves) adolescents were asked directly whether or not they are currently a member of a gang. Those responding with a yes in any of the Waves 2-7 were considered gang members. In addition, at Waves 1, 2, 3, 5, and 7, the adolescents were asked whether or not they have gone through a gang initiation in the past year. Those responding with a yes in any of the Waves 2-7 were considered gang initiators. The responses for membership and initiation were combined to create a broader measure of gang involvement. Second, a polytomous variable was created with those reporting no membership or initiation throughout the course of the study categorized as no gang involvement (coded 0), those reporting both membership and initiation in Waves 2-7 categorized as gang members (coded as 1), and those reporting gang initiation and no membership in Waves 2-7 categorized as initiation only (coded as 2). To ensure proper temporal ordering, adolescents who reported membership and/or initiation at the first wave of the study $(n=13)$ were eliminated from the sample. This approach allowed us to examine gang involvement more broadly, while also examining the effect of each risk factor on membership and initiation separately.

\section{Independent Variables}

All of the risk factors were taken from Wave 1 of the study (adolescents were 10-12) and were used to predict any gang involvement in Waves 2-7 (adolescents were ages 11-18). Because of the large number of risk factors examined, we allowed the total $N$ s for each analysis to vary, which ranged from 626 to 646 (number of missing items: mean $[M]=6$; median $=2.5$ ). A large majority $(87.6 \%)$ had complete data for all items. For ease of presentation, we organized risk factors by their developmental domain (i.e., family, school, peer, individual, and early delinquency). A summary of each measure along with their descriptive statistics and source are displayed in Table 1. 
Table I. Summary Description and Descriptive Statistics for Variables Included in Analyses.

\begin{tabular}{|c|c|c|c|c|c|}
\hline & Summary Description & Mean & $S D$ & Min-Max & $\alpha$ \\
\hline \multicolumn{6}{|l|}{ Dependent variables } \\
\hline Gang membership & $\begin{array}{l}\text { Single item asking whether or not } \\
\text { participants are a member of a gang } \\
(0=\text { no, I = yes }) \text { at Waves } 2-7\end{array}$ & 0.06 & & $0-1$ & \\
\hline Gang initiation & $\begin{array}{l}\text { Single item asking whether or not } \\
\text { participants ever went through a gang } \\
\text { initiation at Waves } 2-7\end{array}$ & 0.09 & & $0-1$ & \\
\hline \multicolumn{6}{|l|}{ Family characteristics } \\
\hline Per capita family income & $\begin{array}{l}\text { Total household income divided by } \\
\text { number of people living in household } \\
\text { (divided by } 1,000 \text { ) }\end{array}$ & 5.44 & 4.04 & $0-25$ & \\
\hline Parental monitoring & $\begin{array}{l}\text { Six items asked to adolescents about } \\
\text { their caretakers monitoring of their } \\
\text { whereabouts such as "how often } \\
\text { does someone know where you are?" } \\
(0=\text { never, } 2=\text { always }) \text {-items } \\
\text { summed }\end{array}$ & 2.88 & 1.86 & $0-9$ & .50 \\
\hline Family member in gang & $\begin{array}{l}\text { One question asked adolescent } \\
\text { respondents whether a family } \\
\text { member is in a gang }(0=\text { no, I = yes })\end{array}$ & 0.12 & & $0-1$ & \\
\hline Caretaker education & $\begin{array}{l}\text { One question asked caretakers what } \\
\text { their highest level of education is } \\
(0=\text { less than high school, } 5=\text { advanced } \\
\text { degree })\end{array}$ & 2.36 & 0.83 & $\mathrm{I}-5$ & \\
\hline \multicolumn{6}{|l|}{ School adjustment } \\
\hline $\begin{array}{l}\text { Low school adjustment, (Crawford, } \\
\text { Cheadle, \& Whitbeck, 20I0) }\end{array}$ & $\begin{array}{l}\text { Thirteen questions asked respondents } \\
\text { whether they agree or disagree } \\
(0=\text { agree, I = disagree) with } \\
\text { statements about school such as } \\
\text { "I like school"-items summed }\end{array}$ & 0.89 & 1.38 & $0-7$ & .70 \\
\hline Trouble at school & $\begin{array}{l}\text { Two questions asked respondents } \\
\text { whether they have "gotten into } \\
\text { trouble with classmates at school" } \\
\text { and whether they have "gotten in } \\
\text { trouble in school" ( } 0=\text { no to both } \\
\text { questions, I = yes to one or both } \\
\text { questions) }\end{array}$ & 0.62 & & $0-1$ & \\
\hline \multicolumn{6}{|l|}{ Peer relationships } \\
\hline Peer delinquency & $\begin{array}{l}\text { Seven questions asked respondents how } \\
\text { many of their three best friends } \\
(0=\text { zero friends, } 3=\text { three friends) } \\
\text { engage in delinquent behavior such as } \\
\text { "getting in trouble in school" and } \\
\text { "drink alcohol"-items averaged }\end{array}$ & 0.61 & 0.57 & $0-3$ & .76 \\
\hline Peer gang involvement & $\begin{array}{l}\text { One question asked respondents } \\
\text { whether they have a friend who is in a } \\
\text { gang }(0=\text { no, } \mathrm{I}=\text { yes })\end{array}$ & 0.10 & & $0-1$ & \\
\hline Early dating & $\begin{array}{l}\text { One question asked respondents } \\
\text { whether they had a steady boyfriend/ } \\
\text { girlfriend }(0=\text { no, I = yes })\end{array}$ & 0.28 & & $0-1$ & \\
\hline
\end{tabular}


Table I. (continued)

\begin{tabular}{|c|c|c|c|c|c|}
\hline & Summary Description & Mean & $S D$ & Min-Max & $\alpha$ \\
\hline \multicolumn{6}{|l|}{ Individual characteristics } \\
\hline Negative life events & $\begin{array}{l}\text { Thirteen questions asked respondents } \\
\text { whether they had experienced } \\
\text { negative life events ( } 0=\text { no, I = yes) in } \\
\text { the past I } 2 \text { months such as "parental } \\
\text { divorce/separation" and "moved } \\
\text { homes"-items summed }\end{array}$ & 3.64 & 2.42 & $0-13$ & .64 \\
\hline $\begin{array}{l}\text { Perceived racial discrimination } \\
\text { (Landrine \& Klonoff, 1996) }\end{array}$ & $\begin{array}{l}\text { Twelve adapted items asked } \\
\text { respondents how often they have } \\
\text { perceived discrimination due to their } \\
\text { culture ( } 0=\text { never, } 2=\text { many times }) \\
\text { such as "someone yelled a racial slur } \\
\text { at you" }\end{array}$ & 9.98 & 3.08 & $0-24$ & .79 \\
\hline $\begin{array}{l}\text { Depressive symptoms (CES-D; } \\
\text { Radloff, 1977) }\end{array}$ & $\begin{array}{l}\text { Nineteen questions asked respondents } \\
\text { how often they experienced } \\
\text { symptoms of depression in the past } \\
\text { week ( } 0=\text { none of the time, } 3=\text { most } \\
\text { or all of the time)-items summed }\end{array}$ & 10.64 & 3.49 & $0-23$ & .84 \\
\hline $\begin{array}{l}\text { Anger, (Swaim, Oetting, Edwards, \& } \\
\text { Beauvais, 1989) }\end{array}$ & $\begin{array}{l}\text { Six questions asked respondents how } \\
\text { often they feel angry }(0=\text { none of the } \\
\text { time, } 2=\text { most of the time }) \text { such "quick } \\
\text { tempered" and "getting mad" }\end{array}$ & 4.59 & 2.36 & $0-12$ & .76 \\
\hline $\begin{array}{l}\text { Hyperactivity/impulsivity (Diagnostic } \\
\text { Interview Schedule for Children IV; } \\
\text { Shaffer, Fisher, Lucas, Dulcan, \& } \\
\text { Schwab-Stone, 2000) }\end{array}$ & $\begin{array}{l}\text { Nine questions asked how often } \\
\text { respondents experienced symptoms } \\
\text { associated with ADHD }(0=\text { no, I = } \\
\text { yes) such as interrupting people when } \\
\text { they are talking-items summed }\end{array}$ & 4.52 & 2.73 & $0-9$ & .80 \\
\hline \multicolumn{6}{|l|}{ Early delinquency } \\
\hline $\begin{array}{l}\text { General delinquency (Diagnostic } \\
\text { Interview Schedule for Children IV; } \\
\text { Shaffer et al., 2000) }\end{array}$ & $\begin{array}{l}\text { Twenty-eight questions asked } \\
\text { respondents whether they have } \\
\text { engaged in delinquent behaviors in } \\
\text { the past } 12 \text { months }(0=\text { no, I = yes) } \\
\text { such as shoplifting and starting } \\
\text { physical fights }\end{array}$ & 2.80 & 3.50 & $0-19$ & .80 \\
\hline Ever used tobacco & $\begin{array}{l}\text { One question asked whether } \\
\text { respondents have ever smoked } \\
\text { cigarettes }(0=\text { no, I }=\text { yes })\end{array}$ & 0.30 & & $0-1$ & \\
\hline Ever used alcohol & $\begin{array}{l}\text { One question asked whether } \\
\text { respondents have ever had more than } \\
\text { a sip of beer, wine, or liquor }(0=n o, I \\
=\text { yes })\end{array}$ & 0.16 & & $0-1$ & \\
\hline Ever used marijuana & $\begin{array}{l}\text { One question asked whether } \\
\text { respondents have ever smoked } \\
\text { marijuana }(0=\text { no, I }=\text { yes })\end{array}$ & 0.11 & & $0-1$ & \\
\hline
\end{tabular}

Note. $N=646$. CES-D $=$ Center for Epidemiologic Studies Depression Scale.

\section{Analytic Strategy}

Most of the cumulative risk studies use dichotomous predictors by splitting continuous variables at the median (Thornberry et al., 2003) or top/bottom quartile (Esbensen et al., 2009; Hill et al., 1999). One potential problem with this approach is that artificial dichotomization of variables may 
attenuate correlations and reduce statistical power necessary to detect significant relationships (Cohen, 1983) and cut points are often arbitrary (Decker, Melde, \& Pyrooz, 2013). Dichotomization removes a lot of information from the variables and ignores similarly across the range of a risk factor (especially at the cut points). Further, gang involvement is a relatively rare event; thus, the combination of dichotomous risk factors and small numbers of gang-involved youth potentially limits the statistical power needed to properly identify predictors of gang involvement. We opted to keep each risk factor in their original metric, rather than dichotomize them.

In the first set of analyses, we compared adolescents who reported any gang involvement (membership and/or initiation) in Waves 2-7 of the study with those not reporting any gang involvement throughout the study (any involvement vs. no involvement). Because this outcome is dichotomous, logistic regression was used. In the second set of analyses, we examined the relative risk of gang membership and gang initiation only versus no gang involvement. Because this variable is nominal with more than two categories, multinomial logistic regression was used. We lacked statistical power to include an extensive array of control variables and test for alternative theoretical explanations. Instead, for each of the dependent variables, we ran each risk factor as its own model with four relevant demographic controls. First, gender has been shown to be a consistent correlate of Indigenous gang involvement with males having a greater likelihood than females of joining a gang (Major et al., 2004; Whitbeck et al., 2002). Second, we adjusted our estimates by age at the first wave of the study to control for possible early developmental differences by age cohort. Third, we included a measure that assesses whether or not respondents were living on or off reservation land (but within 50 miles of it). Fourth, we controlled for whether or not adolescents were living in a remote community, meaning the community is not fully accessible by road at all times of the year. These last two variables account for possible geographic differences.

\section{Results}

The top portion of Figure 1 displays the total number of gang involvement cases at each wave along with the cumulative prevalence across the study. A small number of adolescents reported gang membership $(6.6 \%$ cumulative prevalence; $n=43)$ or gang initiation $(9.1 \%$ cumulative prevalence; $n=59)$ during Waves 2-7 of the study. The adolescents were also asked the name of the gang they were a member of. The most common responses included Native Mob, Native (Gangster) Disciples, (Native) Vice Lords, and the Bloods. Gang membership prevalence peaked by the fifth wave of the study, which is when the participants were 14-16 years of age (prevalence across time: Wave $2-1.2 \%$, Wave 3-1.0\%, Wave 5-2.7\%, and Wave 7-1.7\%). The highest level of gang initiation, however, occurred at the second wave of the study (participants were 11-13 years old), suggesting that gang initiation is slightly more prevalent at younger ages than gang membership (prevalence across time: Wave $2-3.4 \%$, Wave $3-1.4 \%$, Wave $5-2.8 \%$, and Wave $7-1.5 \%$ ). The bottom portion of Figure 1 also displays the convergence across the gang membership and initiation measures over time. The convergence across the two measures was low at Waves 2 and 3 but increased at the last two waves examined.

Males were significantly more likely than females to report gang involvement (males: $16.6 \%$, females: $7.1 \% ; \chi^{2}=14.14, p<.001$ ). Moreover, in all of the subsequent logistic regression models, males consistently had double the odds of gang involvement than females (results not shown). There were no differences between gang-involved and nongang-involved youth with regard to age at the start of the study, living on/off the reservation/reserve, or living in a remote location.

\section{Predictors of Gang Involvement}

The first column of Table 2 shows the results for our expanded measure of gang involvement. Those reporting any membership and/or initiation in Waves 2-7 were compared to those reporting no gang 


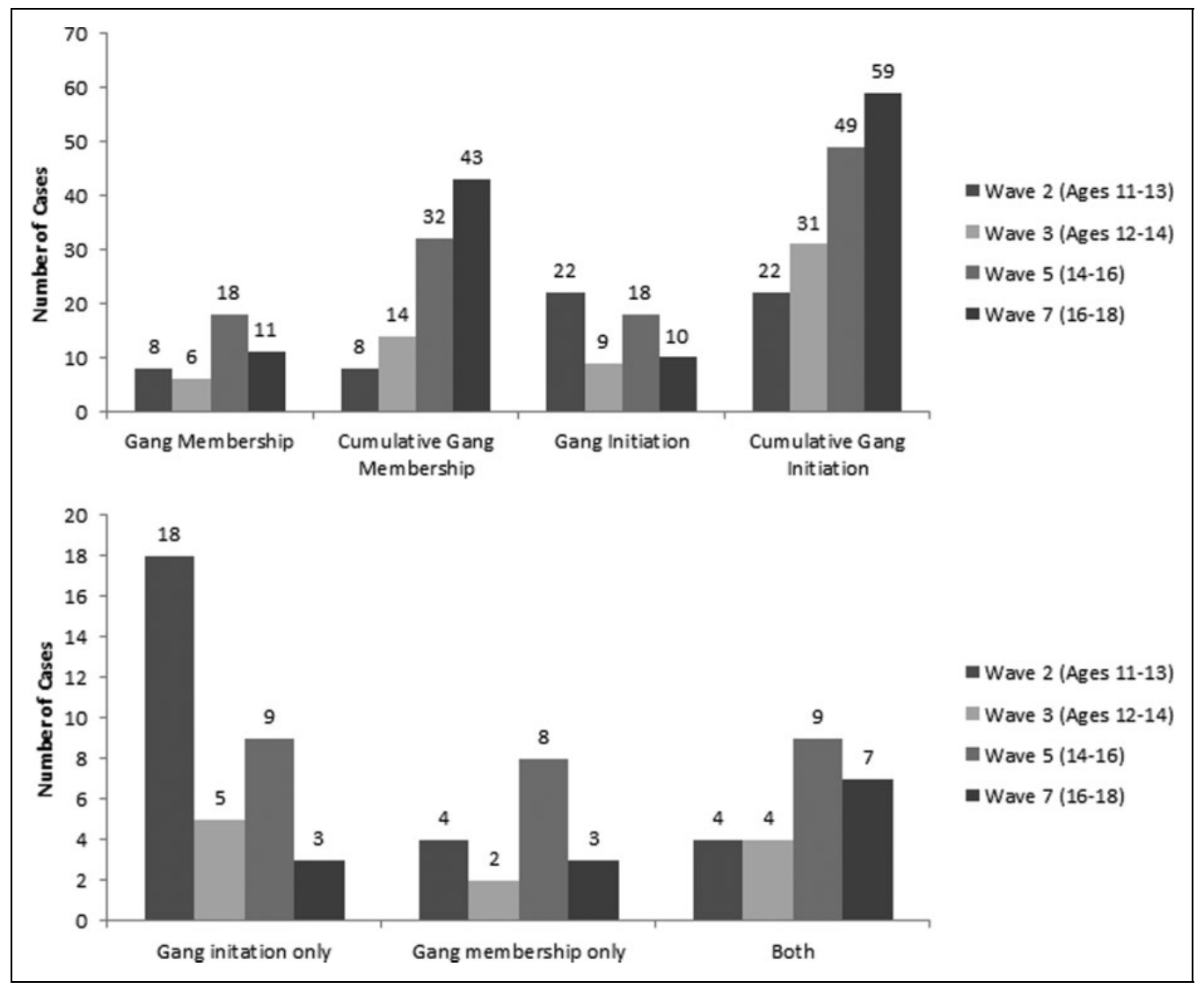

Figure I. Gang involvement prevalence across time (top portion) and convergence of measures across time (bottom portion).

involvement throughout the entire course of the study. The last two columns display the multinomial logistic regression models that separate the measures out into no gang involvement, gang membership, and gang initiation only (no gang involvement is the reference group).

Family characteristics. Of the four family characteristics, only per capita family income and parental monitoring were significant predictors of gang involvement. Higher levels of family income decreased the odds of later gang involvement. This relationship, however, was being driven by gang membership. The multinomial logistic regression results indicate that compared to gang members higher levels of family per capita income increase the odds of initiation only (results not shown). Thus, family income appears to exert the strongest risk for gang membership. Low parental monitoring was associated with higher odds of gang involvement; however, the multinomial logistic regression model indicated that this finding was largely driven by adolescents who reported gang initiation only. Having a family member in a gang and parent education were not significant predictors.

School adjustment. School adjustment did not predict gang involvement; however, in the multinomial logistic regression models lower levels of school adjustment increased the relative risk of gang initiation only compared to no gang involvement. Getting in trouble at school was associated with 
Table 2. Logistic Regression Models Predicting Gang Involvement (Adjusted for Demographic (haracteristics ${ }^{\mathrm{a}}$ ).

\begin{tabular}{|c|c|c|c|}
\hline & \multirow[b]{2}{*}{ Gang Involvement ${ }^{\mathrm{b}}$} & \multicolumn{2}{|c|}{ No Gang Involvement vs. } \\
\hline & & Membership ${ }^{c}$ & Initiation Only ${ }^{c}$ \\
\hline & OR & RRR & RRR \\
\hline \multicolumn{4}{|l|}{ Family characteristics } \\
\hline Family member in gang & $1.92^{\dagger}$ & 1.73 & 2.16 \\
\hline Parent education & 0.77 & 0.79 & 0.75 \\
\hline Per capita family income & $0.90 * *$ & $0.82 * *$ & 0.97 \\
\hline Low parental monitoring & $1.21 * *$ & $1.18^{\dagger}$ & $1.24 *$ \\
\hline \multicolumn{4}{|l|}{ School adjustment } \\
\hline Low school bonding & 1.13 & 1.02 & $1.25 *$ \\
\hline Trouble at school & $2.36 * *$ & $2.97 *$ & 1.18 \\
\hline \multicolumn{4}{|l|}{ Peer relationships } \\
\hline Peer delinquency & $1.83 * *$ & 1.43 & $2.38 * *$ \\
\hline Peer gang involvement & $2.53 * *$ & 2.07 & $3.11 *$ \\
\hline Early dating & $1.94 *$ & $\mathrm{I} .67$ & $2.34 *$ \\
\hline \multicolumn{4}{|l|}{ Individual characteristics } \\
\hline Negative life events & $\mathrm{I} . \mathrm{II} *$ & 1.06 & $1.19 *$ \\
\hline Perceived racial discrimination & $1.15^{* * *}$ & $\mathrm{I} . \mathrm{II} *$ & $1.19 * * *$ \\
\hline Depressive symptoms & $1.05 * *$ & $1.05 *$ & $1.04 *$ \\
\hline Anger & 1.07 & I.0I & $1.15^{*}$ \\
\hline Hyperactivity/impulsivity & $1.16 * *$ & $1.20 * *$ & $1.12^{\dagger}$ \\
\hline \multicolumn{4}{|l|}{ Early delinquency } \\
\hline General delinquency & $1.15^{* * *}$ & $1.16 * * *$ & $1.15^{* * *}$ \\
\hline Ever used tobacco & 4.19*** & $4.52 * * *$ & $3.81 * * *$ \\
\hline Ever used alcohol & $4.80 * * *$ & $3.52 * *$ & $6.89 * * *$ \\
\hline Ever used marijuana & $3.47 * * *$ & 1.45 & $7.48 * * *$ \\
\hline \multicolumn{4}{|l|}{ Cumulative risk } \\
\hline Total number of risk factors & $1.26 * * *$ & $1.22 * * *$ & $1.32 * * *$ \\
\hline
\end{tabular}

Note. $\mathrm{OR}=$ odds ratio; $\mathrm{RRR}=$ relative risk ratio.

${ }^{a}$ Adjusted for gender, age at the start of the study, living in a remote community, and living on/off reservation land. ${ }^{b}$ Binary Logistic Regression Models-Each risk factor was run as its own model with demographic controls. 'Multinomial Logistic Regression Models-Each risk factor was run as its own model with demographic controls (no gang involvement is the reference group).

${ }^{\dagger} p<.10 ; *_{p}<.05 ; * * p<.01 ; * * p<.001$.

gang involvement; however, the results for the general gang involvement model were being driven by gang membership and not initiation.

Peer relationships. All three of the peer relationship variables were associated with general gang involvement but not gang membership. As expected, higher levels of delinquent peer associations, having a friend in a gang, and early dating all increased the odds of general gang involvement compared to adolescents who were not gang involved. The multinomial logistic regression models indicated that these associations were being driven by adolescents reporting gang initiation only.

Individual characteristics. Early negative life events increased the odds of general gang involvement. The multinomial logistic regression model suggested that this relationship was being driven by adolescents who reported gang initiation only. Perceived racial discrimination and depressive symptoms 


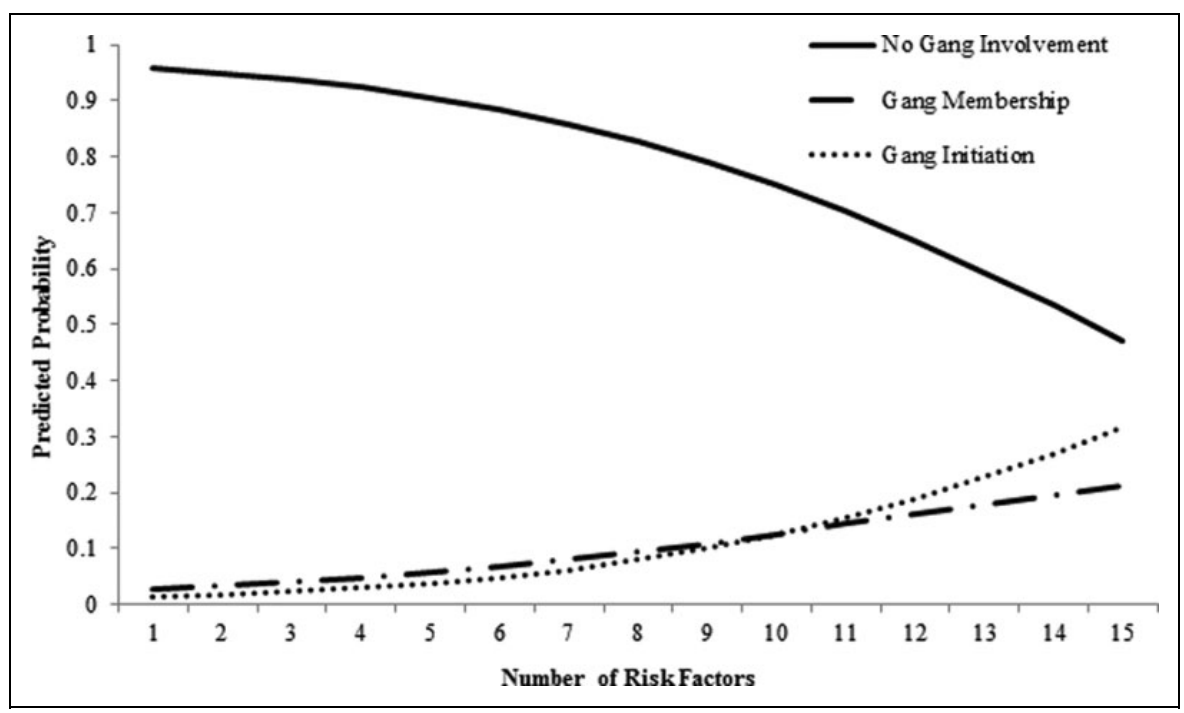

Figure 2. Predicted probabilities of gang involvement at various levels of cumulative risk.

both increased the odds of gang involvement. Anger temperament was not associated with gang involvement; however, the multinomial logistic regression model indicated that anger increased the relative risk of gang initiation only compared to no gang involvement. Hyperactivity/impulsivity increased the odds of gang involvement. The multinomial logistic regression model, however, suggested that this relationship was being driven by gang membership and not initiation.

Early delinquency. All four of the early delinquency variables increased the odds of later gang involvement. The only exception to this pattern was for early marijuana initiation. Adolescents who reported ever trying marijuana at the first wave of the study had increased odds of gang initiation only but not gang membership specifically.

\section{Cumulative Risk}

We created a cumulative risk measure by splitting continuous variables at the top or bottom quartile (i.e., per capita income and parental education) and summing them together with the already dichotomous items $(M=3.82 ; S D=3.00 ; \mathrm{Min} / \mathrm{Max}=0-14)$. We also created an alternative measure by standardizing each variable and averaging them together (as suggested by Iselin, Gallucci, \& DeCoster, 2013; $M=-0.01 ; S D=0.47 ; \operatorname{Min} / \operatorname{Max}=-1.06-1.54)$. This measure takes into account not only whether a risk factor is present, but also the level at which it occurs. Further, this type of measure preserves as much information from the original items as possible. As hypothesized, higher levels of cumulative risk (either measure) increased the odds of gang involvement. To further probe this relationship, we calculated the summed predicted probabilities for each category of our gang involvement variable across levels of cumulative risk (dichotomous risk factors). As shown in Figure 2, at the lowest level of cumulative risk the predicted probability of no gang involvement is .96 . At the highest level of cumulative risk, the predicted probability of no gang involvement drops to .47 . Figure 2 is also disaggregated by gang membership and gang initiation only. At the highest level of cumulative risk, the predicted probability of gang membership and gang initiation only is .21 and .32, respectively (note: the probability of gang involvement is the inverse of no gang involvement or the combined probability of gang membership and gang initiation only). The analyses using 
the standardized risk indicators are similar to those using the dichotomous risk factors; however, the predicted probability of gang membership and gang initiation only are slightly higher suggesting a slight attenuation effect when using dichotomous risk factors (predicted probability .23 and .35 , respectively). These results clearly show that early cumulative risk increases the probability of subsequent gang involvement.

\section{Discussion}

Research on North American Indigenous populations has been largely absent from the mainstream criminological literature, which impedes our understanding of the general and unique risk and protective factors salient to this population. This absence, in turn, limits the extent to which effective gang prevention and intervention programming can be developed and implemented within rural reservation/reserve communities. The purpose of this study was to examine the prevalence of and risk factors for gang involvement among a large sample of Indigenous youth. To our knowledge, this is the first study to use a prospective longitudinal design with an Indigenous population, which is essential in identifying risk factors that precede actual gang involvement (Curry et al., 2014; Drake \& Melde, 2014; Howell \& Egley, 2005; Krohn \& Thornberry, 2008). Furthermore, this study examined a much larger array of risk factors than previous Indigenous gang studies (e.g., Donnermeyer et al., 1996; Freng et al., 2012; Whitbeck et al., 2002). In general, the findings suggest that risk factors are distributed across ecological domains and accumulate to predict subsequent gang involvement.

Overall, our cumulative prevalence rate of adolescent gang involvement is similar to that found in previous cross-sectional studies of Indigenous youth (Donnermeyer et al., 1996; Whitbeck et al., 2002). We found that $6.7 \%$ of our sample reported gang membership which is slightly higher than the $5.3 \%$ found in Whitbeck, Hoyt, Chen, and Stubben's (2002) study and the $6 \%$ for males in the Donnermeyer, Edwards, Chavez, and Beuvais (1996) study. These gang membership estimates are similar but slightly lower than the $8 \%$ cumulative prevalence rate found in the National Longitudinal Study of Youth (Pyrooz, 2013) and the 9.1\% prevalence estimate in the Gang Resistance Education and Training (G.R.E.A.T.) study (Esbensen et al., 2009). In addition, our finding of greater male involvement in gangs is supported by previous studies of Indigenous youth (Donnermeyer et al., 1996; Grant \& Feimer, 2007; Hailer \& Hart, 1999; Major et al., 2004; Whitbeck et al., 2002) and nationally representative samples (Pyrooz, 2013). Our findings, however, diverge from a recent study of Indigenous youth in Grades 6-12 by Freng, Davis, McCord, and Roussell (2012). Their study showed that $27 \%$ of the youth reported current or lifetime gang membership. In addition, our cumulative prevalence estimate diverges from the Rochester Youth Development Study, which found that about a third of the adolescents reported gang membership during the high school years (Thornberry et al., 2003). Both of these studies also found no significant differences in gang membership between males and females.

In addition to our membership estimates, we examined participation in a gang initiation. Our results show that $9.1 \%$ of adolescents reported going through a gang initiation. This estimate is similar to the $12 \%$ found in the American Indian sample of the Add Health study (McNulty \& Bellair, 2003) but significantly higher than the $5 \%$ estimate found in the general overall sample (e.g., Barnes et al., 2010). Although our finding that more adolescents reported gang initiation than actual membership seems counterintuitive, several factors may help explain this phenomenon. Most notably, all three of the peer-level risk factors were associated with initiation only but not actual gang membership. These findings were surprising given the robustness of peerlevel factors for gang membership found in previous research. This suggests that our gang initiation measure likely taps into some informal peer groups that may be loosely organized or peripheral to gangs, or what Grekul and LaBoucane-Benson (2008) labeled in their study 
of Indigenous gangs in Edmonton, Canada as "wannabes." Alternatively, participants who report initiation only may be reluctant to identify as actual gang members introducing a certain level of measurement error. In any case, we feel this measure taps into a broader conceptualization of gang involvement, rather than membership specifically. Moreover, only two variables (per capita family income and marijuana use) differentiated the gang membership and gang initiation groups, suggesting that the two measures are quite similar to one another with regard to ecological risk.

\section{Risk Factors for Gang Involvement}

The results suggest a tentative theoretical model that largely aligns with Vigil's $(1988,2002)$ multiple marginality framework, along with other more established developmental models such as Thornberry's interactional theory (Thornberry, 1987; Thornberry et al., 2003). Historical processes and loss/trauma responses have shaped the developmental context for Indigenous youth and the communities in which they reside (Whitbeck et al., 2014). The insights from the broader historical loss/trauma literature (e.g., Braveheart, 2003) and Whitbeck et al.'s (2014) model of Indigenous development provide a conceptual bridge to Vigil's $(1988,2002)$ well-known multiple marginality framework (see Hailer, 2008 for similar application). Intergenerational influences (e.g., forced relocation, boarding schools, continued assaults on tribal sovereignty, etc.) have led to economically marginalized reservation/reserve communities and weakened social control mechanisms. Weakened family and school systems may lead to delinquent peer involvement and behaviors, which reciprocally interact with individual and other meso-level (e.g., community, family, and school) systems to heighten gang risk. These factors, in turn, may be considered the fundamental causes which propel Indigenous youth into gangs and links history with contemporary proximal risk factors. As such, we argue that future inquiries into Indigenous delinquency and gangs require a more focused understanding of the historical, contemporary, and cumulative processes stemming from the legacy of historical cultural losses.

Within the family, we found low per capita income and parental monitoring to be significant risk factors for gang involvement. Economic hardship may undermine positive parenting practices, which in turn, increase the odds of delinquency (Conger et al., 1992). In addition, we found that low school bonding increases the risk of initiation only, whereas early conduct problems in grade school increase the odds of later gang membership. Many rural and reservation schools are economically challenged (Khattri, Riley, \& Kane, 1997), which can undermine the development of social bonds with this important socializing agent. The combination of early family disadvantage and low school bonding may decrease one's stake in conformity and increase the likelihood of drifting into delinquent peer groups (e.g., Thornberry, 1987). As previously noted our results suggest that peer-level risk factors are only significant for initiation only and not gang membership. This is surprising given the robustness of peer variables in previous studies of Indigenous (Freng et al., 2012) and urban adolescents (Klein \& Maxson, 2006).

Further, the environmental contexts in which adolescents are embedded shape the stressors to which they are exposed and their emotional states. Our results indicate that early negative life events increase the odds for gang initiation. Moreover, early levels of perceived racial discrimination increased the odds of gang membership and gang initiation, which supports prior research among Indigenous youth (Whitbeck et al., 2002). Because gangs are typically socially marginalized, more research is needed in the broader gang literature examining the role discriminatory experiences as a risk factor for gang involvement. In addition, we found that anger was associated with gang initiation, whereas depressive symptoms and hyperactivity/impulsivity were associated with gang membership. These early stressful experiences and emotional strains may interact with other domains of risk (e.g., family, school, and peer) to increase the attraction of gangs. 
All four early delinquency variables significantly increased the odds of later gang involvement. In particular, the three substance use variables nearly tripled the odds of later gang involvement. These findings are supportive of Hill, Howell, Hawkins, and Battin-Pearson (1999) and Thornberry et al. (2003) in which early initiation of alcohol and marijuana increased the odds of gang involvement. Moreover, these results support those that find general substance use behaviors as a correlate of gang involvement among Indigenous youth (Donnermeyer et al., 1996; Whitbeck et al., 2002). Given the early onset of substance use behaviors among this group (Bachman et al., 1991), interventions aimed at preventing or delaying the onset of alcohol, marijuana, and cigarette use may indirectly reduce gang involvement.

The results indicate a possible selection effect wherein delinquent youth select into deviant peer groups and gangs. Although there is limited evidence in the literature for a pure selection model (e.g., Esbensen \& Huizinga, 1993; Thornberry et al., 2003), the results show that compared to those who are not gang involved, those reporting any gang involvement had high levels of delinquency prior to becoming involved in a gang. Once these adolescents become gang involved, peer influences combined with the rural context of the reservation/reserve may enhance these youths' already elevated rates of delinquent behavior. Using the gang initiation measure in the Add Health study, McNulty and Bellair (2003) found that gang involvement partially explained Indigenous youths' greater involvement in delinquency relative to Whites. Thus, an enhancement model (Thornberry et al., 1993) may be a likely scenario, which is commonly found in the urban gang literature (Curry et al., 2014). Future research is needed to determine whether a selection, facilitation, or enhancement (Thornberry et al., 1993) model best describes reservation/reserve residing Indigenous youth.

More importantly, the accumulation of risk in late childhood is what likely propels youth into gangs. Early environmental and individual level disadvantage may set in motion cumulative processes wherein youth fail to develop strong social bonds and drift away from conventional institutions and behaviors, which place them on developmental trajectories conducive to gang involvement. Our results suggest that cumulative risk increases the relative risk of gang involvement, which supports previous research (Esbensen et al., 2009; Hill et al., 1999; Thornberry et al., 2003). We found, however, that at the highest level of cumulative risk there is only about a $50 \%$ probability of gang involvement. Stated differently, it indicates that even the most at-risk youth are more likely to not join a gang than end up in one during adolescence.

Similar findings were reported by Thornberry and colleagues (2003), who found that the highest level of cumulative risk, only about two fifths of their sample were gang members. These findings suggest that there is much variation in gang involvement that is not being accounted for by cumulative risk. Clearly, there are missing factors that important for gang formation and involvement such as community level factors (Klein \& Maxson, 2006) and other interpersonal level risks such as victimization (Pyrooz, Moule, \& Decker, 2014). These results suggest that there may be unique sources of resilience that inhibits gang involvement for the most at-risk youths who do not join gangs. Moreover, it suggests the possibility that a complex set of specific risk factors interact with one another to increase the odds of gang involvement, rather than the simple accumulation of risk. Nevertheless, the results do show a clear cumulative risk effect and provide useful insights into the risk factors salient for Indigenous gang involvement.

\section{Limitations}

Despite the usefulness of the cumulative risk approach, several limitations are inherent that warrant discussion. Although many of these issues have been raised previously (e.g., Decker et al., 2013), we reiterate several points that are germane to this study. First, this type of analytic approach assumes additive, rather than interactive effects. Grekul and LaBoucane-Benson (2008) noted that for Indigenous youth, risk factors interact and exacerbate one another. Moreover, factors salient for rural 
reservation/reserve residing youth such as geographic isolation, historical cultural losses, and lack of cultural identity likely magnify the effect these risk factors. It is probable that certain risk factors are only important in the context other risk factors, or enhance the effects of other variables. Unfortunately, examining all possible two way and higher order interactive effects is not feasible. Similarly, this type of modeling approach gives all risk factors equal weight in the cumulative risk score, when it is possible that certain risk factors are more influential than others. Second, we were unable to rule out spuriousness outside of the included control variables. Several of the significant findings may be a result of some third variable associated with both the risk factor and gang involvement (e.g., selfcontrol). Multivariate analyses would allow us to address some of these limitations; however, there is limited statistical power to conduct more complex analyses due to the small number of ganginvolved youth.

Third, this modeling approach does not account for possible mediating mechanisms linking childhood risk with later adolescent gang involvement. For example, conceptual models have been developed to explain adolescent gang involvement, in which dynamic early risk factors are linked with later gang membership through multiple unfolding developmental life course pathways (e.g., Howell \& Egley, 2005; Thornberry et al., 2003). Our conceptualization of risk is static in nature in that it is only assessed at one specific time point. It is possible that risk factors vary as a function of timing in the life course (dynamic approach). Recent evidence, however, indicates that the effect of risk and protective factors on gang involvement do not vary as a function of age (Gilman, Hill, Hawkins, Howell, \& Kosterman, 2014). Thus, the risk factors identified in this study are likely to remain salient for gang involvement across the course of adolescence. Because little gang research exists among Indigenous adolescents, and to our knowledge, no other study has been able to establish proper temporal ordering, we believe this analytic approach is well suited to identify early risk factors among this population that can be used to develop prevention and intervention programming.

Fourth, the findings of this study may not be generalizable to all Indigenous groups in the United States and Canada, and perhaps even to urban Indigenous adolescents of the same cultural group. Because of cultural and geographic heterogeneity, Whitbeck and colleagues (2014) argued that research among Indigenous groups should accrue tribal nation by nation, rather than making comparisons across different Indigenous cultural groups. Although North American Indigenous populations share a common history of colonization and contemporary socioeconomic disadvantage, the ways in which these things shape contemporary risk among different Indigenous tribal and cultural groups may vary. For example, geographic location may play a vital role in Indigenous gang involvement in that proximity to urban centers increases the likelihood of gang migration from large urban areas to reservation/reserves and opportunities for gang involvement (Hailer \& Hart, 1999). Moreover, variations reservation/reserve size dictates the amount of law enforcement presence and differential ability to suppress gangs (Armstrong et al., 2002). Future research on Indigenous gangs should proceed by cultural group. The accumulation of knowledge across different Indigenous groups will provide vital information on similarities and difference across tribal nations and geographic areas.

\section{Implications}

Overall, we found that the risk factors for gang involvement among this sample are similar to those found in the extant urban gang literature (see Curry et al., 2014; Klein \& Maxson, 2006; Krohn \& Thornberry, 2008 for reviews), which suggests that preexisting gang prevention/intervention programs should work among reservation/reserve youth. Yet the conditions which shape ecological risk among this population likely stem from different social and historical processes, making the risk factors identified similar in function, but different in context (Whitbeck et al., 2014). This contention is 
argued by Vigil (2002) in which similar subcultural processes unfold across places and groups, however, sociohistorical factors make specific racial and ethnic groups unique in certain ways. This has important implications for how we conceptualize, design, and implement gang prevention and intervention programs among Indigenous youth residing on reservations/reserves.

The results of the current study suggest a clear need for early childhood prevention and intervention efforts. In addition, these programs need to target multiple developmental deficits across ecological domains. Although few gang prevention and intervention programs have been shown to be effective (see Klein \& Maxson, 2006), a more recent evaluation of the G.R.E.A.T. program (Esbensen, Peterson, Taylor, \& Osgood, 2012), showed a significant decrease in gang involvement in part because it targeted a more expansive range of risk factors. Caution must be used when trying to apply these types of programs to rural Indigenous communities. Any gang prevention effort must be culturally adapted to fit the developmental context in which Indigenous adolescents are embedded to embrace their unique world view and to capitalize on local community and cultural strengths (Whitbeck et al., 2014). This also limits the possibility of accepting what Klein and Maxson (2006) refer to as "conventional wisdoms" and assuming "that what we learn about successful anti-gang programming in one location can fairly well be applied to other locations" (p. 135).

\section{Declaration of Conflicting Interests}

The author(s) declared no potential conflicts of interest with respect to the research, authorship, and/or publication of this article.

\section{Funding}

The author(s) disclosed receipt of the following financial support for the research, authorship, and/or publication of this article: This research was supported by the National Institute on Drug Abuse under grant (DA13580); National Institute of Mental Health under grant (MH67281); and National Institute on Alcohol Abuse and Alcoholism under grant (1R01AA020299-01A1) awarded to L. Whitbeck.

\section{References}

Agnew, R. (1992). Foundation for a general strain theory of crime and delinquency. Criminology, 30, 47-87. Armstrong, T., Bluehouse, P., Dennison, A., Mason, H., Mendenhall, B., Wall, D., \& Zion, J. (2002). Finding and knowing the gang Nayee: Field-initiated gang research project, the judicial branch of the Navajo Nation. Washington, DC: Office of Juvenile Justice and Delinquency Prevention.

Bachman, J., Wallace, J., O’Malley, P., Johnston, L., Kurth, C., \& Neighbors, H. (1991). Racial/ethnic differences in smoking, drinking, and illicit drug use among American high school seniors, 1976-89. American Journal of Public Health, 81, 372-377.

Barnes, J., Beaver, K., \& Miller, J. M. (2010). Estimating the effect of gang membership on nonviolent and violent delinquency: A counterfactual analysis. Aggressive Behavior, 36, 437-451.

Braveheart, M. Y. H. (2003). The historical trauma response among Natives and its relationship with substance abuse: A Lakota illustration. Journal of Psychoactive Drugs, 35, 7-13.

Bell, J., \& Lim, N. (2005). Young once, Indian forever: Youth gangs in Indian country. American Indian Quarterly, 29, 626-650.

Cohen, J. (1983). The cost of dichotomization. Applied Psychological Measurement, 7, 249-253.

Collins, W. A. (2003). More than myth: The developmental significance of romantic relationships during adolescence. Journal of Research on Adolescence, 13, 1-24.

Conger, R., Conger, K., Elder, G., Lorenz, F., Simons, R., \& Whitbeck, L. (1992). A family process model of economic hardship and adjustment of early adolescent boys. Child Development, 63, 526-541.

Craig, W. M., Vitaro, F., Gagnon, L., \& Tremblay, R. E. (2002). The road to gang embership: Characteristics of male gang and nongang members from ages 10 to 14. Social Development, 11, 53-68. 
Crawford, D., Cheadle, J., \& Whitbeck, L. (2010). Tribal vs. public schools: Perceived discrimination and school adjustment among Indigenous children from early to mid-adolescence. Journal of American Indian Education, 49, 86-106.

Curry, G. D., Decker, S., \& Pyrooz, D. (2014). Confronting gangs: Crime and community (3rd ed.). New York, NY: Oxford University Press.

Decker, S., Melde, C., \& Pyrooz, D. (2013). What do we know about gang and gang members and where do we go from here? Justice Quarterly, 30, 369-402.

Decker, S., Pyrooz, D., Sweeten, G., \& Moule, R. (2014). Validating self-nomination in gang research: Assessing differences in gang embeddedness across non-, current, and former gang members. Journal of Quantitative Criminology, 30, 577-598.

Dishion, T. J., Nelson, S. E., \& Yasui, M. (2005). Predicting early adolescent gang involvement from middle school adaptation. Journal of Clinical Child and Adolescent Psychology, 34, 62-73.

Donnermeyer, J. F., Edwards, R. W., Chavez, E. L., \& Beauvais, F. (1996). Involvement of American Indian youth in gangs. Free Inquiry in Creative Sociology, 24, 167-174.

Drake, G., \& Melde, C. (2014). The problem of prediction: The efficacy of multiple marginality in crosssectional versus prospective models. Journal of Crime and Justice, 37, 61-78.

Dupéré, V., Lacourse, É., Willms, J. D., Vitaro, F., \& Tremblay, R. E. (2007). Affiliation to youth gangs during adolescence: The interaction between childhood psychopathic tendencies and neighborhood disadvantage. Journal of Abnormal Child Psychology, 35, 1035-1045.

Esbensen, F., \& Huizinga, D. (1993). Gangs, drugs, and delinquency in a survey of urban youth. Criminology, $31,565-589$.

Esbensen, F., Peterson, D., Taylor, T. J., \& Freng, A. (2009). Similarities and differences in risk factors for violent offending and gang membership. Australian \& New Zealand Journal of Criminology, 42, 310-335.

Esbensen, F., Peterson, D., Taylor, T., \& Osgood, W. (2012). Results from a multi-site evaluation of the G.R.E.A.T. program. Justice Quarterly, 29, 125-151.

Esbensen, F., Winfree, L. T., He, N., \& Taylor, T. J. (2001). Youth gangs and definitional issues: When is a gang a gang, and why does it matter? Crime \& Delinquency, 47, 105-130.

Farrington, D. P. (2000). Explaining and preventing crime: The globalization of knowledge - the American society of criminology 1999 presidential address. Criminology, 38, 1-24.

Freng, A., Davis, T., McCord, K., \& Roussell, A. (2012). The new American gang? Gangs in Indian Country. Journal of Contemporary Criminal Justice, 28, 446-464.

Freng, A., \& Esbensen, F. (2007). Race and gang affiliation: An examination of multiple marginality. Justice Quarterly, 24, 600-628.

Gilman, A., Hill, K., Hawkins, J. D., Howell, J., \& Kosterman, R. (2014). The developmental dynamics of joining a gang in adolescence: Patterns and predictors of gang membership. Journal of Research on Adolescence, 24, 204-219.

Gordon, R., Lahey, B., Kawai, E., Loeber, R., Stouthamer-Loeber, M., \& Farrington, D. (2004). Antisocial behavior and youth gang membership: Selection and socialization. Criminology, 42, 55-88.

Grant, C., \& Feimer, S. (2007). Street gangs in Indian Country: A clash of cultures. Journal of Gang Research, $14,27-66$.

Grekul, J., \& LaBoucane-Benson, P. (2008). Aboriginal gangs and their (dis)placement: Contextualizing recruitment, membership, and status. Canadian Journal of Criminology and Criminal Justice, 50, 59-82.

Hailer, J. (2008). American Indian youth involvement in urban street gangs: Invisible no more? Unpublished doctoral dissertation, University of Arizona, Tucson.

Hailer, J., \& Hart, C. (1999). A new breed of warrior: The emergence of American Indian youth gangs. Journal of Gang Research, 7, 23-33.

Hill, K. G., Howell, J. C., Hawkins, J. D., \& Battin-Pearson, S. R. (1999). Childhood risk factors for adolescent gang membership: Results from the Seattle social development project. Journal of Research in Crime and Delinquency, 36, 300-322. 
Howell, J. C., \& Egley, A. (2005). Moving risk factors into developmental theories of gang membership. Youth Violence and Juvenile Justice, 3, 334-354.

Iselin, A. -M. R., Gallucci, M., \& DeCoster, J. (2013). Reconciling questions about dichotomizing variables in criminal justice research. Journal of Criminal Justice, 41, 386-394.

Joseph, J., \& Taylor, D. (2003). Native American youths and gangs. Journal of Gang Research, 10, 45-54.

Khattri, N., Riley, K., \& Kane, M. (1997). Students at risk in poor, rural areas: A review of the research. Washington, DC: Pelavin Research Institute.

Klein, M., \& Maxson, C. (2006). Street gang patterns and policies. New York: Oxford University Press.

Krohn, M. D., \& Thornberry, T. P. (2008). Longitudinal perspectives on adolescent street gangs. In A. M. Liberman (Ed.), The long view of crime: A synthesis of longitudinal research (pp. 128-160). New York: Springer.

Krohn, M., Ward, J., Thornberry, T., Lizotte, A., \& Chu, R. (2011). The cascading effects of adolescent gang involvement across the life course. Criminology, 49, 991-1028.

Lahey, B. B., Gordon, R. A., Loeber, R., Stouthamer-Loeber, M., \& Farrington, D. P. (1999). Boys who join gangs: A prospective study of predictors of first gang entry. Journal of Abnormal Child Psychology, 27, 261-276.

Landrine, H., \& Klonoff, E. A. (1996). The schedule of racist events: A measure of racial discrimination and a study of its negative physical and mental health consequences. Journal of Black Psychology, 22, 144-168.

Major, A., \& Egley, A. (2002). 2000 survey of youth gangs in Indian Country. Washington, DC: Office of Juvenile Justice and Delinquency Prevention.

Major, A. K., Egley, A., Jr, Howell, J. C., Mendenhall, B., \& Armstrong, T. (2004). Youth gangs in Indian Country. Washington, DC: US Department of Justice, Office of Justice Programs, Office of Juvenile Justice and Delinquency Prevention.

McNulty, T., \& Bellair, P. (2003). Explaining racial and ethnic differences in serious adolescent violent behavior. Criminology, 41, 709-747.

National Gang Intelligence Center. (2011). 2011 National gang threat assessment: Emerging trends. Washington, DC: National Gang Intelligence Center.

Peterson, D., \& Morgan, K. A. (2014). Sex differences and the overlap in youths' risk factors for onset of violence and gang involvement. Journal of Crime and Justice, 37, 129-154.

Pyrooz, D. C. (2013). "From your first cigarette to your last dyin' day": The patterning of gang membership in the life-course. Journal of Quantitative Criminology, 30, 349-372.

Pyrooz, D. C. (2014). From colors and guns to caps and gowns? The effects of gang membership on educational attainment. Journal of Research in Crime and Delinquency, 51, 56-87.

Pyrooz, D., Moule, R., \& Decker, S. (2014). The contribution of gang membership to the victim-offender overlap. Journal of Research in Crime and Delinquency, 51, 315-348.

Radloff, L. S. (1977). The CES-D scale: A self-report depression scale for research in the general population. Applied Psychological Measurement, 1, 385-401.

Shaffer, D., Fisher, P., Lucas, C. P., Dulcan, M. K., \& Schwab-Stone, M. E. (2000). NIMH Diagnostic Interview Schedule for Children Version IV (NIMH DISC-IV): Description, differences from previous versions, and reliability of some common diagnoses. Journal of the American Academy of Child and Adolescent Psychiatry, 39, 28-38.

Swaim, R. C., Oetting, E. R., Edwards, R. W., \& Beauvais, F. (1989). Links from emotional distress to adolescent drug use: A path model. Journal of Consulting and Clinical Psychology, 57, 227-231.

Taylor, T. J., Peterson, D., Esbensen, F., \& Freng, A. (2007). Gang membership as a risk factor for adolescent violent victimization. Journal of Research in Crime and Delinquency, 44, 351-380.

Theriot, M., \& Parker, B. (2008). Native American youth gangs: Linking culture, history, and theory for improved understanding prevention and intervention. Journal of Ethnicity in Criminal Justice, 5, 83-97.

Thornberry, T. (1987). Toward and interactional theory of delinquency. Criminology, 25, 863-892.

Thornberry, T. P., Krohn, M. D., Lizotte, A. J., \& Chard-Wierschem, D. (1993). The role of juvenile gangs in facilitating delinquent behavior. Journal of Research in Crime and Delinquency, 30, 55-87. 
Thornberry, T., Krohn, M., Lizotte, A., Smith, C., \& Tobin, K. (2003). Gang membership and delinquency: Gangs in developmental perspective. New York: Cambridge University Press.

United States Census Bureau. (2006). We the people: American Indians and Alaska Natives in the United States. Washington, DC: Author.

Unnever, J. D., Cullen, F. T., \& Pratt, T. C. (2003). Parental management, ADHD, and delinquent involvement: Reassessing Gottfredson and Hirschi's general theory. Justice Quarterly, 20, 471-500.

Vigil, J. D. (1988). Barrio gangs: Street life and identity in Southern California. Austin, TX: University of Texas Press.

Vigil, J. D. (1996). Streep baptism: Chicano gang initiation. Human Organization, 55, 149-153.

Vigil, J. D. (2002). A rainbow of gangs: Street cultures in the mega-city. Austin: University of Texas Press.

Whitbeck, L. B., Hoyt, D. R., Chen, X., \& Stubben, J. D. (2002). Predictors of gang involvement among American Indian adolescents. Journal of Gang Research, 10, 11-26.

Whitbeck, L., Sittner Hartshorn, K., \& Walls, M. (2014). Indigenous adolescent development: Psychological, social and historical contexts. New York: Psychology Press.

\section{Author Biographies}

Dane S. Hautala is a PhD candidate in sociology at the University of Nebraska-Lincoln. His research focuses on delinquency and mental health among North American Indigenous youth.

Kelley J. Sittner, PhD, is an assistant professor in the Department of Sociology at Oklahoma State University. She received her PhD in sociology in 2011 from the University of Nebraska-Lincoln. Her research focuses on antisocial behavior, mental health, and substance use among adolescents.

Les B. Whitbeck, $\mathrm{PhD}$, is professor emeritus in the Department of Sociology at the University of Nebraska-Lincoln. He is principal investigator of an 8-year diagnostic study of American Indian children aged 10 to 12 years. He has authored or coauthored two books on homeless adolescents, one book on Indigenous adolescent development, and more than 130 refereed journal articles. He received the 2007 Community, Culture, and Prevention Science Award from the Society for Prevention Research. 